$$
\text { N } 1=2392 \%
$$

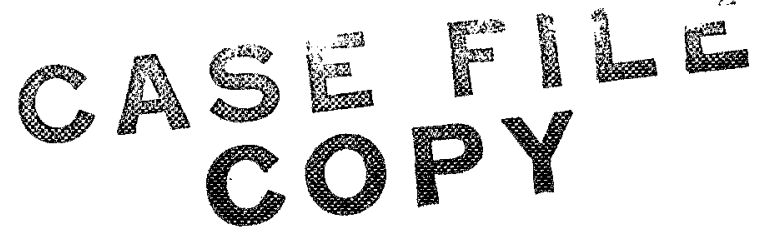

\title{
INSTANTANEOUS AND DYNAMIC ANALYSIS OF SUPERSONIC INLET-ENGINE COMPATIBILITY
}

James E. Calogeras, Paul L. Burstadt, and Robert E. Coltrin Lewis Research Center

Cleveland, Ohio

TECHNICAL PAPER proposed for presentation at

Seventh Propulsion Joint Specialist Conference sponsored by the American Institute of Aeronautics and Astronautics Salt Lake City, Utah, June 14-18, 1971 


\title{
INSTANTANEOUS AND DYNAMIC ANALYSIS OF SUPERSONIC INLET-ENGINE COMPATIBILITY
}

\author{
James E. Calogeras, Paul L. Burstadt, and Robert E. Coltrin \\ National Aeronautics and Space Administration \\ Lewis Research Center \\ Cleveland, Ohio
}

\section{Abstract}

An experimental wind-tunnel investigation was made to determine the effects of time-variant distortions produced in a supersonic inlet on a J85-GE-13 turbojet engine. Results are presented principally in terms of "'instantaneous" distortion amplitudes and contours measured through compressor stall. They indicate that although a time-averaged distortion may be far from a stall-inducing value, corresponding instantaneous distortion amplitudes can approach or exceed this value. A film made by combining instantaneous distortion contours demonstrates that severe total pressure fluctuations at the compressor face can result in an instantaneous distortion of a type completely different from the time-averaged distortion.

\section{Introduction}

It has become apparent that total pressure fluctuations produced in a supersonic inlet can limit its compatibility with a turbo-engine of a propul sion system. When considered at any instant in time, such time-variant pressures can result in a large airflow distortion at the inlet/ engine interface relative to the time-averaged distortion. There is general agreement as to the cause of these fluctuations in an inlet. A major share appears to originate from an unsteady interaction of the terminal shock with the diffuser boundary layer. Also recognized is the effect of time-variant distortion; it can seriously degrade compressor stall margin. Several experimental investigations have already been made which verify both the cause and the effect of time-variant distortion (e.g. , refs. 1-6). Further, such studies have at least qualitatively related the amount of stall margin degradation to the amplitude of the dynamic activity. But the preponderance of data thus far accumulated was recorded either in an environment of artificially created distortion dynamics or in the absence of an engine.

The purpose of this investigation was to measure time-variant distortions produced in a supersonic inlet just prior to compressor stall. An axisymmetric, mixedcompression inlet designed for Mach 2.5 was coupled to a J85-GE-13 turbojet engine. Steady-state and dynamic data were recorded over a range of operating conditions at Mach numbers of 2.5 and 2.6. Results are presented principally in terms of "instantaneous" distortion amplitudes and contours measured through compressor stall. The instantaneous distortion amplitudes are compared with a steady-state correlation. This investigation was conducted in the 10-by 10-Foot Supersonic Wind Tunnel of the NASA-Lewis Research Center.
Apparatus and Procedure

Inlet Details

The inlet used in this investigation was designed for Mach 2.50 and sized to match the airflow requirements of a J85-GE-13 turbojet engine. A photograph of the inlet terminated by a coldpipe-choked plug assembly is shown in Fig. 1 mounted in the Lewis 10-by 10-Foot Supersonic Wind Tunnel. While more complete inlet design and performance details are reported in Ref. 7, some of the more pertinent details are illustrated in Fig. 2. The inlet was an axisymmetric mixed-compression type with 60 percent of the supersonic flow area contraction provided externally. This was accomplished with a biconic centerbody which translated to effect inlet start and off design operation. Internally, the cowl lip shock was cancelled at its impingement point on the centerbody. Further isentropic compression resulted in a throat Mach number of 1.30. Cowl and centerbody boundary layer bleed was provided by perforations in the region of the geometric throat. The compressor face station was segmented by three support struts which extended forward about half the length of the subsonic diffuser. Each of the three duct segments contained two ejector and overboard bypasses which provided engine cooling and off-design airflow matching, respectively. Both the ejector and the overboard bypasses ported flow from a common cavity. A dual-vane cascade was installed at the entrance to each cavity to alleviate a resonance associated with these volumes (cf. ref. 8).

\section{Engine Details}

The General Electric J85-GE-13 is an afterburning turbojet possessing a high thrust-to-weight ratio. The engine consists of an eight-stage axial-flow compressor coupled directly to a two-stage turbine. It incorporates controlled compressor interstage bleed and variable inlet guide vanes, a through-flow annular combustor, and an afterburner (not used in this test) with a variable area primary exhaust nozzle. The engine inlet diameter is $40.9 \mathrm{~cm}$. (16.1 in.).

The exhaust nozzle area was manually controlled for this investigation. The compressor was stalled by slowly closing the nozzle while maintaining a constant engine speed. In order to avoid overtemperaturing the turbine during this procedure, the first-stage turbine nozzle was approximately 14 percent smaller in area than the standard unit. At any point on the compressor map, then, the turbine was matched to the compressor at a lower turbine inlet temperature: Compressor interstage bleed, mechanically linked to the inlet guide vanes, was scheduled linearly from full closed at 90 percent corrected speed to full open at 76 percent corrected speed. The normal schedule actuates the bleed valves between corrected 
speeds of 94 and 80 percent. This modified schedule made the compressor operate with less interstage bleed than normal and therefore with less stall margin.

\section{Instrumentation}

Steady-stage and dynamic pressure instrumentation at the compressor face and compressor discharge stations is presented in Fig. 3. Only the fluctuating component of pressure was recorded from each of the dynamic probes. This component was later added to the time-averaged (steady-state) pressure provided by the adjacent probe. Frequency response of the dynamic compressor face probes was flat to about $2000 \mathrm{~Hz}$. Response of the compressor discharge dynamic pressure probes, as well as an axial row of interstage static probes not shown in this figure, was flat to about $300 \mathrm{~Hz}$. The fluctuating component of each pressure transducer was recorded on FM-multiplexed tape at $152.4 \mathrm{~cm}$. $/ \mathrm{sec} .(60 \mathrm{in} . / \mathrm{sec})$. This speed provided recording capability of up to $4000 \mathrm{~Hz}$.

\section{Results and Discussion}

Compressor performance with undistorted inflow is presented in Fig. 4. These data were recorded in an altitude test facility as part of a program to determine the effect of steady-state distortions on a J85-GE-13 turbojet (cf. ref. 9). This same engine was used in the wind-tunnel investigation of time-variant distortion.

The sensitivity of the compressor to various types of distortion patterns is presented in Fig. 5. These results are from the screen-induced distortion program reported in Ref. 9. Loss in compressor pressure ratio at stall is plotted as a function of a distortion index based on a critical angle of spoiled flow. The $P_{\min , 60^{\circ}}$ used in this figure was defined as the lowest mean pressure in. any $60^{\circ}$ sector of the compressor face flow field (see Appendix B). The data shown in this figure represent stall points from each of the patterns shown. For the two partial radial patterns, the terms used in the distortion index were taken from a ring containing the spoiled sector. For the other patterns, the $P_{\min } 60^{\circ}$ was radially averaged. Although this distortion index takes no account of pure radial distortions, of these only tip radial distortion was found to have an effect on the stall line of the compressor. Hub radial distortion, while it caused a shift in the corrected speed characteristics to lower corrected airflows, did not effect the stall margin of the compressor. And mid-span radial distortions were not found to have any affect on compressor performance. Since these effects were much less than those encountered with circumferential distortion, they are neglected in this particular distortion index. The solid curve faired through the data, then, was used to analyze the timevariant distortion data recorded in the wind tunnel program.

Two stall points recorded during the wind-tunnel test will be discussed in this paper. The corresponding engine operating conditions just prior to stall are presented in Fig. 6. A portion of the compressor map for undistorted inflow is repeated for purposes of comparison. The shift in the corrected speed characteristics is due to a combination of engine speed and inlet distortion effects. Hereinafter these points will be referred to as either the $\alpha=0^{\circ}$ or the $\alpha=5^{\circ}$ stall, where $\alpha$ denotes the inlet angle-of-attack condition. Some 30 -odd stall points were recorded during the entire wind-tunnel program, and of these 12 have been analyzed using the instantaneous distortion approach. In all but two of these cases, instantaneous distortion peaks were found which were at least high enough to cause the demonstrated loss in stall compressor pressure ratio. The $\alpha=0^{\circ}$ and $\alpha=5^{\circ}$ stall points were chosen for presentation for the following reasons: (1) Both stalls occurred during periods when the time-variant distortion amplitudes were significantly higher than the time-averaged, or steady-state levels. (2) They represent two basically different types of steadystate distortion. The steady-state distortion was primarily a hub radial for the $\alpha=0^{\circ}$ stall and a $180^{\circ}$ circumferential for the $\alpha=5^{\circ}$ stall. (3) For both of these stalls, the degradation in stall compressor pressure ratio was much more than would be indicated by the steady-state distortion levels. In fact, if only steady-state distortions were considered, the $\alpha=0^{\circ}$ stall should have occurred somewhere on the undistorted inflow stall line. (4) Both stalls were 'drift' type. That is, the engine conditions had been set and had reached equilibrium, and a steadystate data recording made, when the compressor abruptly stalled..

Steady-state and dynamic pressure contours for the $\alpha=0^{\circ}$ and $\alpha=5^{\circ}$ stalls are presented in Figs. 7(a) and (b), respectively. For simplicity, the centerbody support struts which segment the inlet at the compressor face station were neglected in the construction of these contours. Each shaded area of the steady-state contour map represents a given range of total pressure recovery, with the darkest region representing the lowest recovery. The boundary between any two shaded regions is a constant pressure contour. Each shaded area on the dynamic map represents a given range of total pressure fluctuations. Here the darkest area represents the region of highest dynamic activity. To obtain the dynamic distortion contours, the output signal from each of the compressor face dynamic probes was filtered by a second order low-pass filter with a 1000-Hz corner frequency and measured with a TRMS meter. The RMS amplitude of the fluctuating component of each total pressure was then ratioed to the steady-state compressor face average pressure, and the resulting value used to construct the dynamic contour map.

The data of Fig. 7 (a) were recorded at Mach 2.5 with the inlet operating somewhat supercritically at a to tal pressure recovery of about 79 percent. The distortion is almost purely radial, with the lowest-pressure region occurring at the hub. The corresponding dynamic contour map shows that the region of highest dynamic activity is closer to the tip, or to the region of higher pressure airflow. The data of Fig. $7(\mathrm{~b})$ were recorded at Mach 2.6 with the inlet operating supercritically at a steady-state pressure recovery of about 77 percent. The steady-state contour map shows the distortion to be primarily circumferential, although there is a significant radial component present. The corresponding dynamic contour map indicates that while the RMS level is rela- 
tively low in the region of the lowest pressure recovery, it is even lower in the region of highest pressure recovery. The region of high dynamics, then, again lies in a band located between the high- and low-pressure recovery regions. It will be shown that this region of high dynamics had a major effect on the instantaneous distortion amplitudes which preceeded compressor stall.

Frequency distributions of the power contained in the total pressure fluctuations of three radially-spaced compressor face probes are presented in Fig. 8. They represent about 6.5 seconds of real-time data recorded just prior to the $\alpha=5^{\circ}$ stall. They were made using a spectrum analyzer which simultaneously performed real-time Fourier analyses at all frequencies up to $5000 \mathrm{~Hz}$, within a $10-\mathrm{Hz}$ bandwidth. The auto power spectral density (APSD) plots for probes $\mathrm{B}$ and $\mathrm{C}$ are rather typical of the frequency distributions of probes in the low and high dynamic regions, respectively. The dynamic level of each was fairly flat to about $300 \mathrm{~Hz}$ and then decreased by about 75 percent at $1 \mathrm{kHz}$. The APSD of probe A indicates a resonance at about $300 \mathrm{~Hz}$. Although installation of a cascade in the bypass cavities had successfully eliminated this resonance for most inlet operating conditions, occasional traces of it are still evident in probes located in the vicinity of these cavities.

The circumferential distortion index previously discussed in Fig. 5 was applied on an instantaneous basis to the $\alpha=0^{\circ}$ and $\alpha=5^{\circ}$ stall points. Results are presented in Figs. 9(a) and 9(b), respectively. The analog compressor face pressure data from which these plots were made were filtered at $1600 \mathrm{~Hz}$ and then simultaneously digitized at 8000 points per second per channel. The circumferential distortion index was computed every 0.125 millisecond and plotted over a 50 millisecond time period just before and during compressor stall. It should be noted that the J85-GE-13 compressor rotates about $12.5^{\circ}$ in 0.125 milliseconds. In this discussion, no distinction is made as to whether the circumferential component of the time-variant distortion originated upstream of the compressor in the inlet or originated within the compressor and fed forward to the inlet. This is due to the current inability to determine the effect engine presence may have on time-variant distortion.

The $\mathrm{P}_{\min }, 60^{\circ}$ used in the circumferential distortion index was taken as the lowest average rake pressure for the instantaneous distortion plots of Fig. 9. With this in mind, it is particularly surprising that for the $\alpha=0^{\circ}$ point, several instantaneous distortion peaks exceed a level of 0.08 , and one peak exceeds an amplitude of 0.10 . Remember that the steady-state distortion for the $\alpha=0^{\circ}$ stall was primarily a pure radial type. Based on steadystate pressures, the value of this circumferential distortion index would be only 0.013 . And based on the compressor operating point just prior to the $\alpha=0^{\circ}$ stall, the critical level of circumferential distortion which would cause stall is shown as 0.107 . One distortion peak in the time interval shown exceeds the critical level; that at $t=22.6$ milliseconds. Evidence of complete or abrupt compressor stall was not seen in the interstage static pressure instrumentation until about 19 milliseconds after this time. It is not clear at this date whether the compres- sor stalled as a result of the single peak which exceeded the critical level or as a cumulative result of several peaks which approached or exceeded the critical level, in either the time slot shown or in a longer interval. What is significant is that the total pressure fluctuations produced in an inlet can result in an airflow distortion of a type completely different from the steady-state distortion, and of an amplitude which is intolerable to the engine.

Like the $\alpha=0^{\circ}$ stall, the $\alpha=5^{\circ}$ stall point has only one instantaneous distortion peak which rises above the critical level of 0.147 in the 50 millisecond time interval; that at $t=38.5$ millisecond. Three other peaks in this interval come extremely close to the critical level. Evidence of abrupt compressor stall was seen about 7 milliseconds after the highest distortion peak. Although the steady-state distortion for this point was primarily circumferential, the distortion index based on steady-state pressures is only 0.101 . This is more than 30 percent lower than the critical level.

One aspect of interest concerning both the $\alpha=0^{0}$ and $\alpha=5^{\circ}$ instantaneous distortion peaks which exceeded the critical level is that in neither case did they remain above this level for more than 1 millisecond (or $100^{\circ}$ of rotor rotation). By proper analog filtering or digital averaging, it should be possible to determine the highest frequency content of significance to the engine. Conceptually, with the proper filter and a valid parameter, only the distortion which caused engine stall should exceed the critical level. But for the two points shown, filtering or averaging the data for a time equivalent to more than about $60^{\circ}$ of rotor rotation would attenuate the highest distortion peaks to a value somewhat below the critical level. And as discussed in Ref. 9, the compressor reaction to circumferential distortion varies only as the circumferential extent is increased up to $60^{\circ}$.

Total pressure contours corresponding to the $\alpha=0^{\circ}$ and $\alpha=5^{\circ}$ instantaneous distortion peaks which exceeded the critical level are presented in Figs. 10(a) and $10(\mathrm{~b})$, respectively. They were made from the same digitized data used for the previous figure. The steady-state distortion contours are included for comparison. For the $\alpha=0^{\circ}$ point, the instantaneous contour shows that a large region of extremely low pressure had developed in the lower half of the compressor face plane, and had extended almost the full blade span at the $7 o^{\prime}$ clock position. This is primarily the reason for the high amplitude of the corresponding circumferential distortion index, even though the $P_{\min }, 60^{\circ}$ used in the index was radially averaged. For the $\alpha=5^{\circ}$ point, the instantaneous contour shows the region of low recovery to be in a zone between 5 and $70^{\prime}$ clock. This is similar to the steady-state contour. But in contrast to the steady-state contour, the region of higher-pressure airflow has increased in size, thereby increasing the compressor-face average pressure. Since the distortion amplitude is directly proportional to the difference between average and minimum pressures, the increase in average pressure resulted in an increase in amplitude. Worthy of note is the fact that the extension of higher-pressure airflow occurred over a region coincident with the zone of high dynamics, as previously shown in Fig. 7(b). A film made by combining the 
instantaneous pressure contours in cartoon fashion demonstrates even more graphically that, particularly for this point, a good correlation exists between the high dynamic region on the RMS plot to the spatial area in the motion picture which has the greatest number of pressure boundary crossings per unit of time. From the motion picture it was found that in the upper high-pressure region there were very few boundaries crossing a given spot. In the high dynamic band there were at least four different boundaries passing over a given spot rather frequently. And in the low-pressure region, it was possible to see two different boundaries crossing a given spot frequently, with two others appearing occasionally.

Three compressor interstage static pressure traces are shown in Fig. 11 for the $\alpha=5^{\circ}$ stall point. They are representative of the data recorded from an axial row of piezoelectric-type transducers located at the downstream edge of each stator stage. The time interval, 15-50 milliseconds, corresponds to the same interval in Fig. 9(b). The instantaneous distortion peak which exceeded the critical level, from Fig. 9(b), occurred at $t=38.5 \mathrm{mil}-$ liseconds. At $\mathrm{t}=39.0$ milliseconds, a large drop in the first stage exit pressure occurs and is evident in the seccond and sixth stage exit pressures as well. Since the origin of a stalled zone in a compressor causes an abrupt loss in the airflow pumping of that stage, a compression wave is sent forward of the zone, and an expansion sent rearward. So the drop in the first stage exit pressure appears to indicate that a stall zone originated in that stage. Considering the transport time from the compressor face to the first stage exit (less than 1 millisecond), it is probable that this stall is associated with the distortion peak at $t=38.5$ milliseconds. But it is not clear if this initial stall precipitated the abrupt stall at $t=45$ milliseconds, which appears to have originated between the second and sixth stages. And of the wind-tunnel data thus far analyzed, this is the only case in which an individual peak in the distortion index has been directly related to a stall zone in the compressor.

\section{Concluding Remarks}

A wind-tunnel investigation was made to determine the effects of time-variant distortions produced in a supersonic inlet on a J85-GE-13 turbojet engine. Results are presented principally in terms of "instantaneous" " distortion amplitudes and contours measured through compressor stall. They indicate the following:

1. Although a time-averaged distortion may be far from a stall-inducing value, corresponding instantaneous distortion amplitudes can approach or exceed this value.

2. Severe total pressure fluctuations can result in an instantaneous distortion of a type completely different from the time-averaged distortion.

3. The zone of highest dynamics was found to be in a band located between the high- and low-pressure recovery regions. This zone had a major effect on the instantaneous distortion amplitudes which preceeded compressor stall.

\section{Appendix A}

\section{Symbols}

APSD

auto power spectral density, $\left(\mathrm{N} / \mathrm{m}^{2}\right)^{2} / \mathrm{Hz}$ $\left(\left(\mathrm{lb} / \mathrm{ft}^{2}\right)^{2} / \mathrm{Hz}\right)$

$\begin{array}{ll}\text { M } & \text { Mach number } \\ \mathrm{N} & \text { engine speed, } \mathrm{rpm} \\ \mathrm{N} & \text { rated engine speed, } 16500 \mathrm{rpm}\end{array}$

$\left(\mathrm{N} / \mathrm{N} * \sqrt{\theta_{2}}\right) \times 100$ percent corrected engine speed

$\mathbf{P}$

$P_{\min , 600}$

$\Delta \mathbf{P}$

RMS

$\mathrm{T}$

TRMS

$t$

W

$\mathrm{W}_{\text {corr }}$

$\alpha$

$\beta$

$\delta$

$\theta$

Subscripts

0

2

3

rms

Superscript total pressure, $\mathrm{N} / \mathrm{m}^{2}\left(\mathrm{lb} / \mathrm{ft}^{2}\right)$

lowest mean pressure of any $60^{\circ}$ sector of compressor face flow field, $\mathrm{N} / \mathrm{m}^{2}$ $\left(\mathrm{lb} / \mathrm{ft}^{2}\right)$

fluctuating component of total pressure

root mean square

total temperature, $\mathrm{K}\left({ }^{\circ} \mathrm{R}\right)$

true root mean square

time

engine airflow, $\mathrm{kg} / \mathrm{sec}(1 \mathrm{~b} / \mathrm{sec})$

engine corrected airflow, $\mathrm{W} \sqrt{\theta} / \delta, \mathrm{kg} / \mathrm{sec}$ $(\mathrm{lb} / \mathrm{sec})$

angle of attack, deg

spoiled sector angle, rad

local corrected total pressure, $\mathrm{P} / 101,325 \mathrm{~N} / \mathrm{m}^{2}\left(\mathrm{P} / 2116 \mathrm{lb} / \mathrm{ft}^{2}\right)$

local corrected total temperature, $\mathrm{T} / 288.2 \mathrm{~K}\left(\mathrm{~T} / 518.7^{\circ} \mathrm{R}\right)$

free stream

compressor face station

compressor discharge station

root mean square

average 


\section{Appendix B}

\section{Definition of $P_{\min , 60^{\circ}}$}

$\mathrm{P}_{\min , 60^{\circ}}$ is defined as the lowest mean pressure in any $60^{\circ}$ sector of the compressor face flow field; that is,

$$
\left.\left.\mathrm{P}_{\min , 60^{\circ}}\right)_{2} \equiv \frac{1}{60^{\circ}} \int_{\xi}^{\xi+60^{\circ}} \mathbf{P}_{2}(\alpha) \mathrm{d} \alpha\right] \operatorname{min.~value~}_{\substack{\text { over range } \\ 0^{\circ} \leq \xi \leq 360^{\circ}}}
$$

where

$60^{\circ}$ : critical angle of spoiling for the compressor

$\alpha$ : angular displacement

$\xi$ : dummy variable

An example of this definition for a square wave pressure distribution with a $30^{\circ}$ spoiled sector is shown in the following sketch:

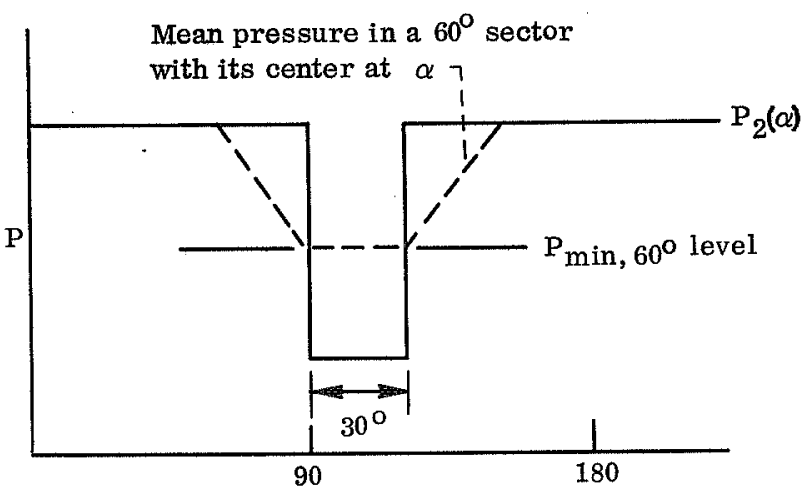

$\alpha, \operatorname{deg}$

\section{References}

1. Kimzey, W. F., "An Investigation of the Effects of Shock-Induced Turbulent Inflow on a YJ 93-GE-3 Turbojet Engine," AEDC-TR-66-198, DDC No. AD-377312L, Nov. 1966, ARO, Inc., Arnold Air Force Station, Tenn.

2.. Burcham, F. W., Jr. and Hughes, D. L., "Analysis of In-Flight Pressure Fluctuations Leading to Engine Compressor Surge in an F-111A Airplane for Mach Numbers to 2.17," Paper 70-624, June 1970, AIAA, New York, N.Y.

3. McAulay, J. E., "Effect of Dynamic Variations in Engine-Inlet Pressure on the Compressor System of a Twin-Spool Turbofan Engine, " TM X-2081, 1970, NASA, Cleveland, Ohio.

4. Martin, A. W., "Propul sion System Flow Stability," Proceedings of the Air Force Airframe-Propulsion Compatibility Symposium, AFAPL-TR-69-103, June 1970, Wright-Patterson AFB, Ohio.
5. Plourde, G. A. and Brimlow, B, "Pressure Fluctuations Cause Compressor Instability, $"$ Proceedings of the Air Force Airframe-Propulsion Compatibility Symposium, AFAPL-TR-69-103, June 1970, WrightPatterson AFB, Ohio.

6. Calogeras, J. E., "Experimental Investigation of Dynamic Distortion in a Mach 2.50 Inlet With 60 Percent Internal Contraction and Its Effect on Turbojet Stall Margin, "TM X-1842, 1969, NASA, Cleveland, Ohio.

7. Sanders, B. W. and Mitchell, G. A., "Increasing the Stable Operating Range of a Mach 2.5 Inlet, " Paper 70-686, June 1970, AIAA, New York, N. Y.

8. Coltrin, R. E. and Calogeras, J. E., "Supersonic Wind Tunnel Investigation of Inlet-Engine Compatibility," Paper 69-487, June 1969, AIAA, New York, N.Y.

9. Calogeras, J. E., Mehalic, C. M., and Burstadt, P. L., "Experimental Investigation of the Effect of Screen-Induced Total Pressure Distortion on Turbojet Stall Margin, "TM X-2239, 1971, NASA, Cleveland, Ohio. 


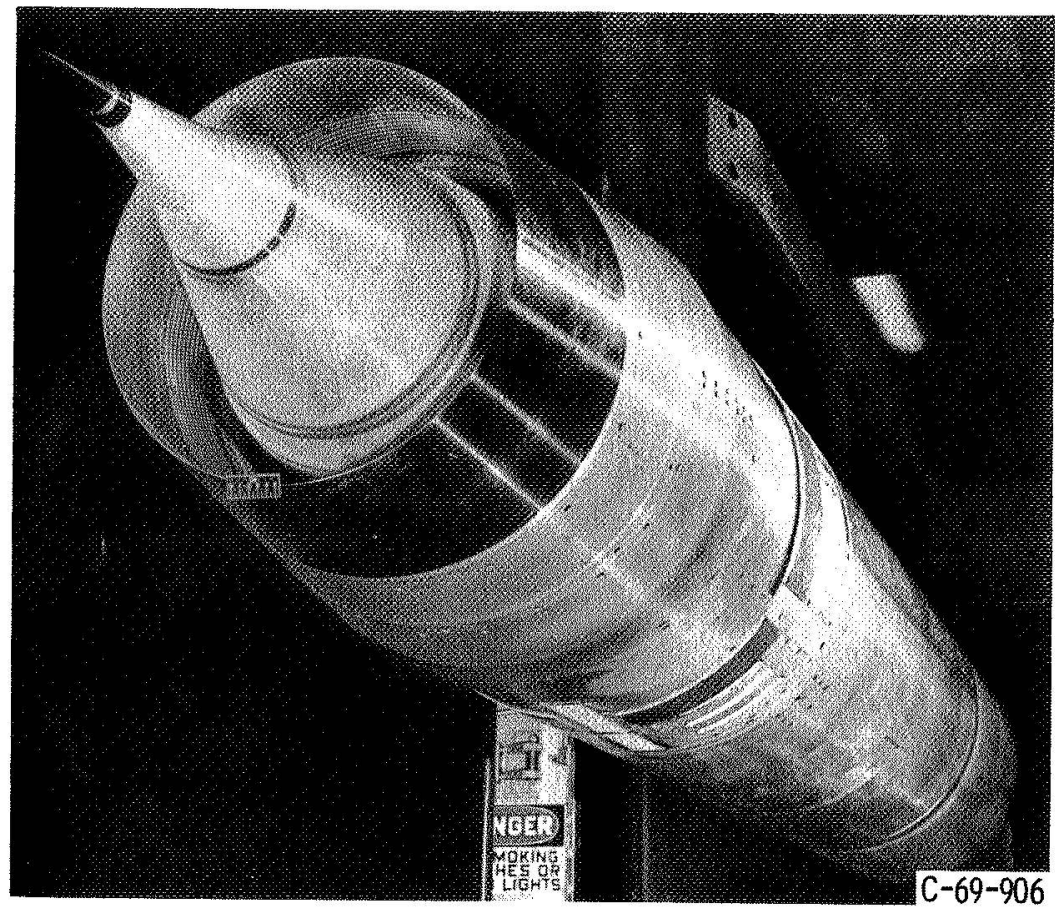

Figure 1. - Inlet-coldpipe installation in 10- by 10-foot Supersonic Wind Tunnel.
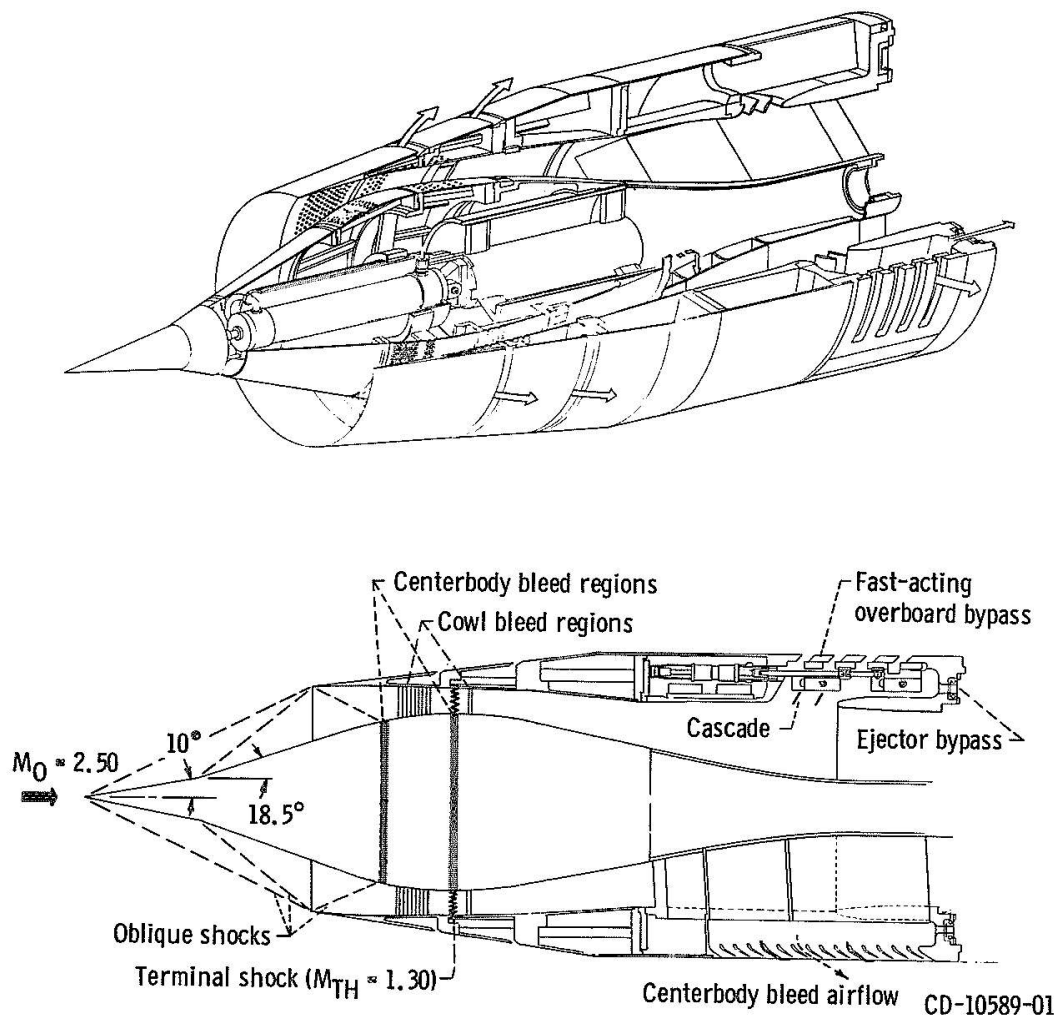

Figure 2. - Inlet details. 

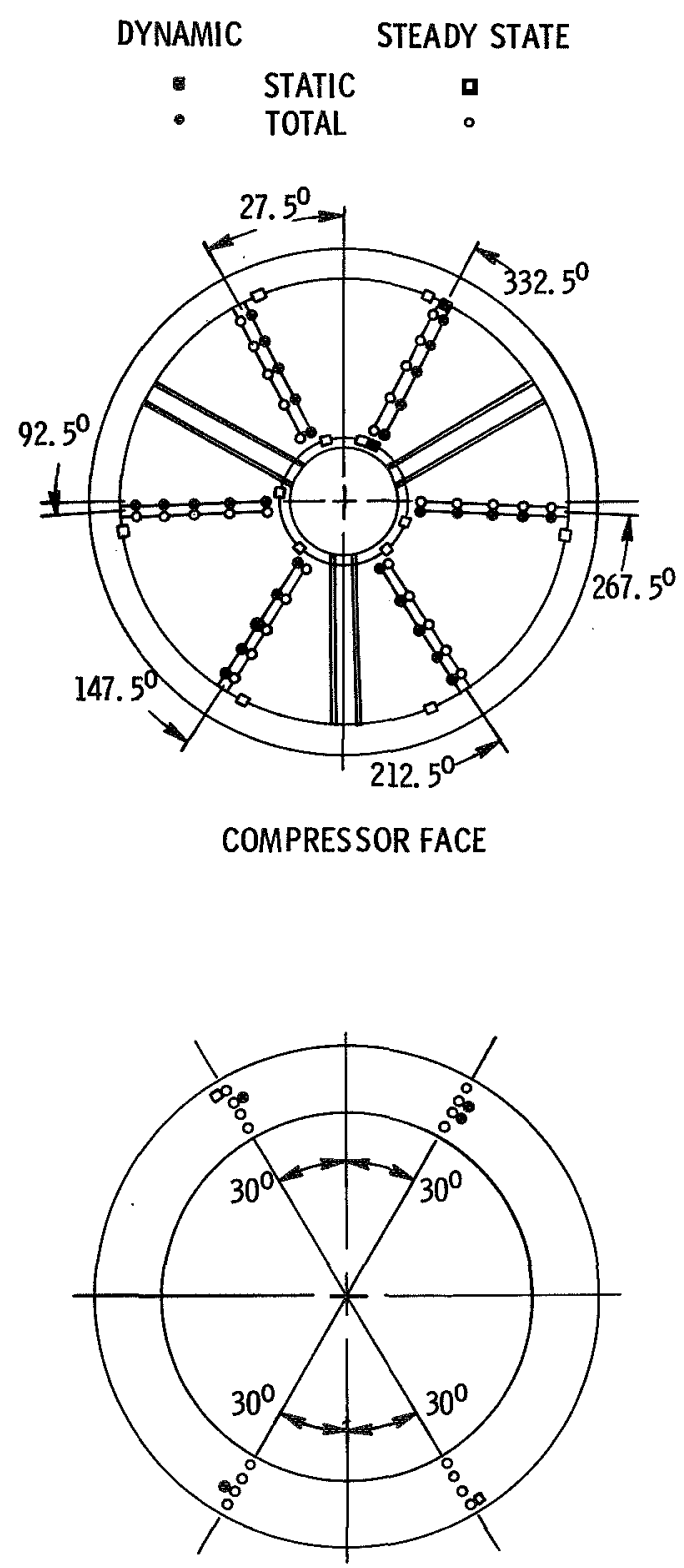

\section{COMPRESSOR DISCHARGE (LOOKING DOWNSTREAM)}

Figure 3. - Steady-state and dynamic pressure instrumentation. 

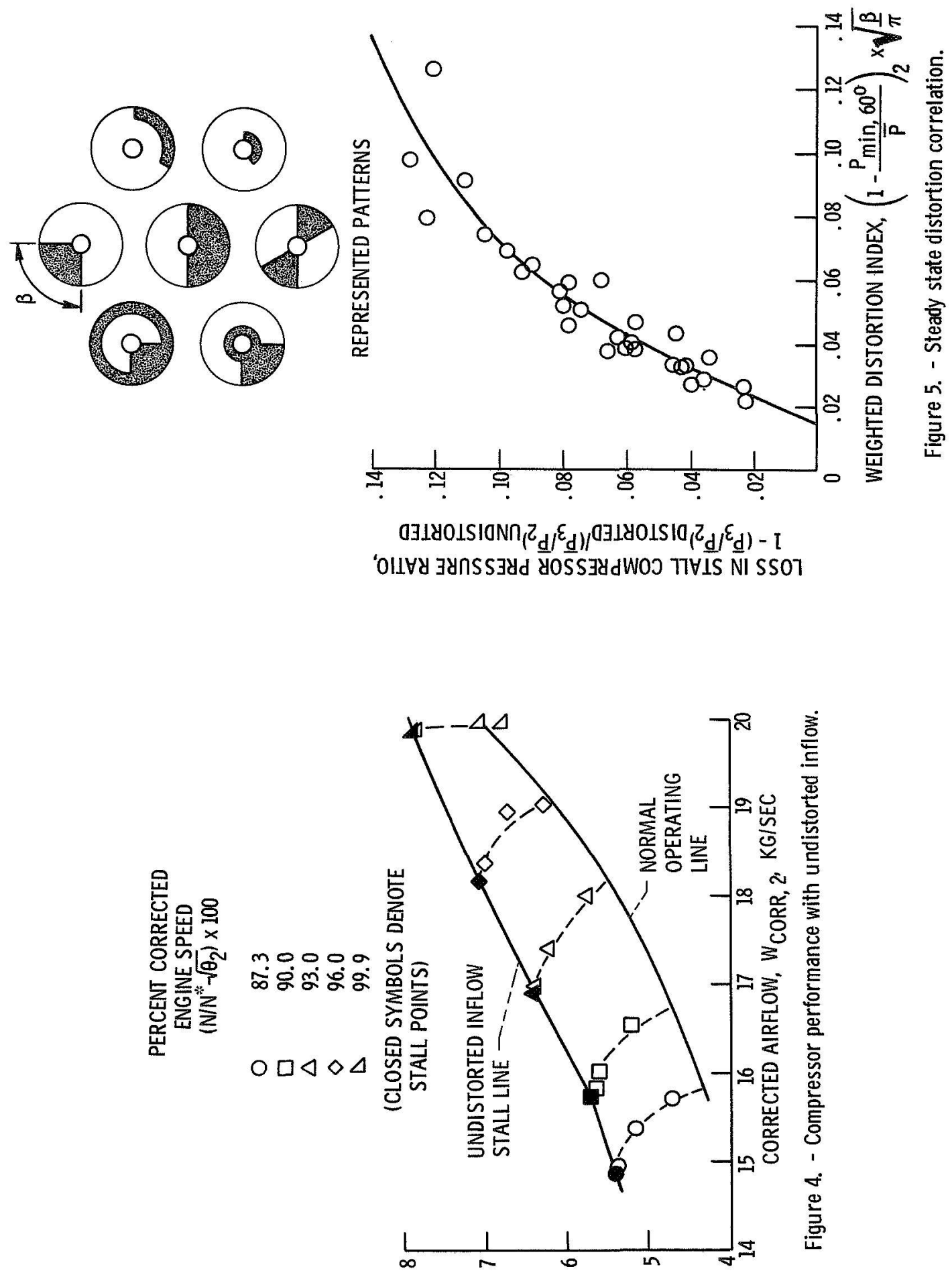

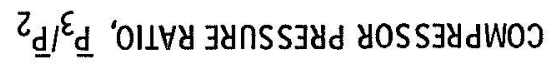




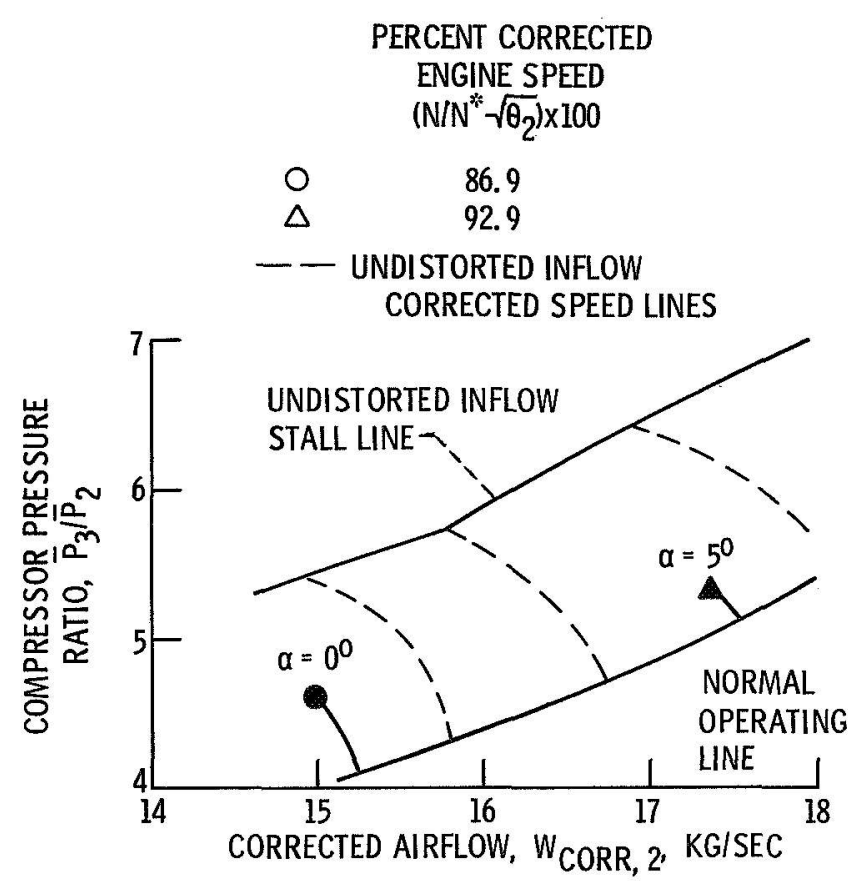

Figure 6. - Compressor performance with inletproduced distortion. 


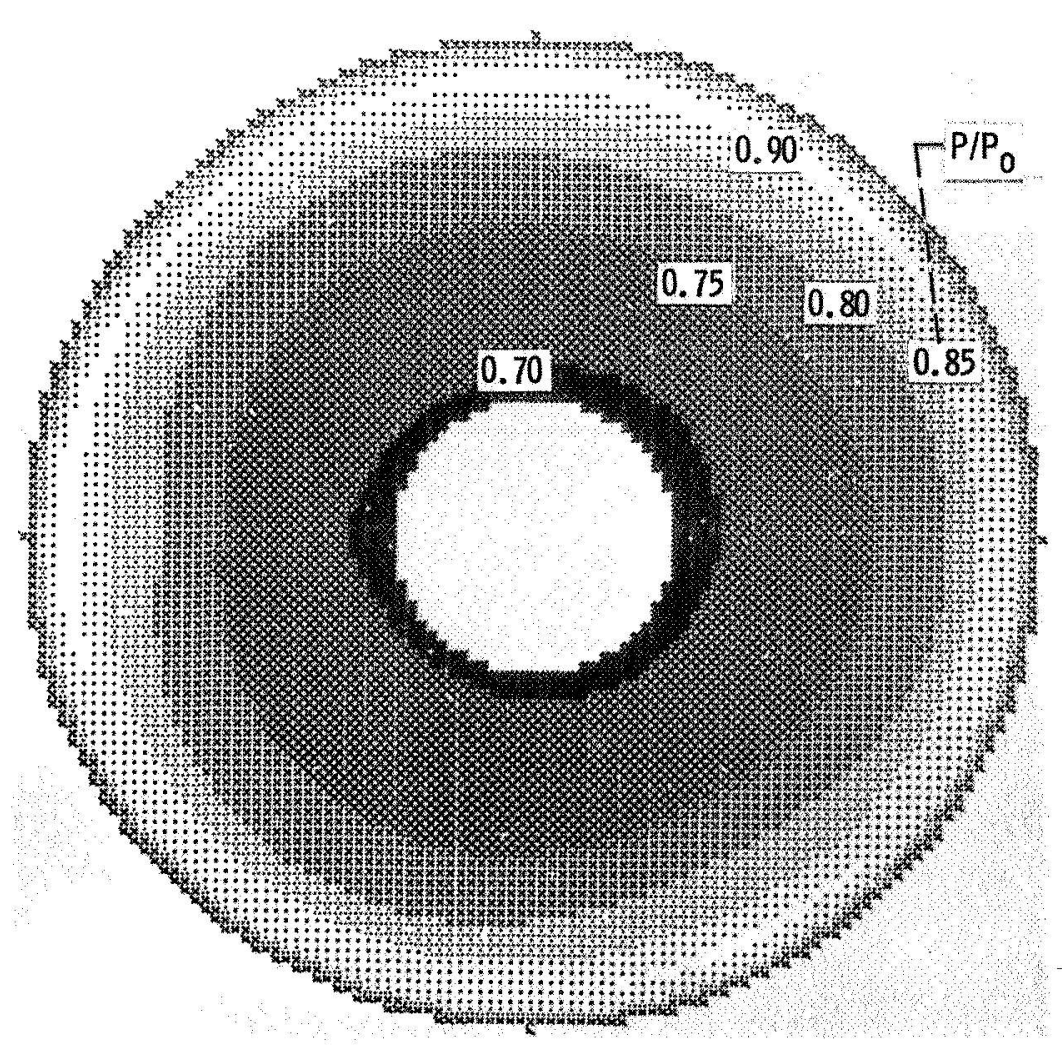

Steady-state; $\overline{\mathrm{P}} / \mathrm{P}_{0}=0.788$.

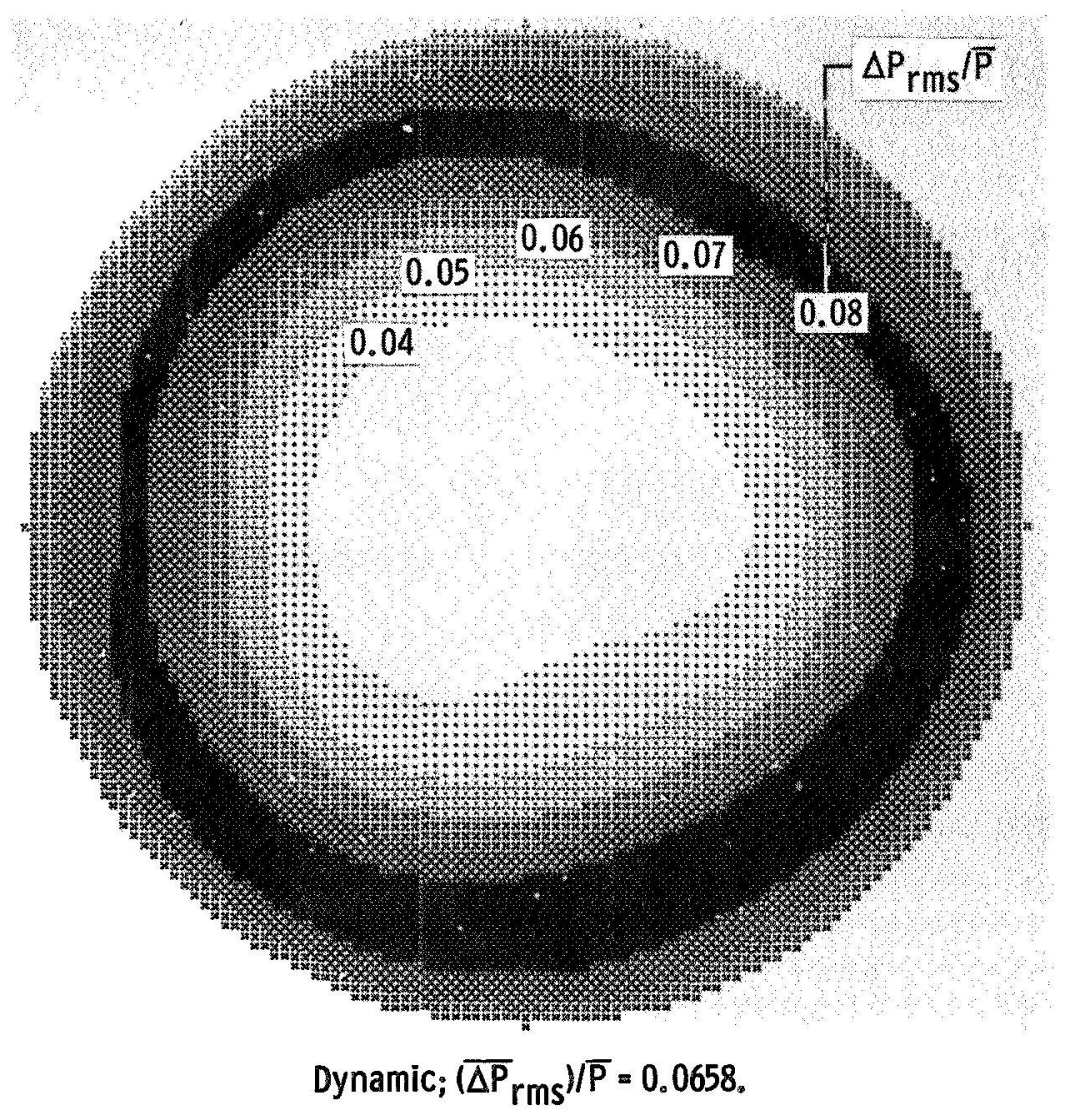

(a) $\alpha=0^{\circ}$ stall point.

Figure 7. - Steady-state and dynamic distortion contours. 


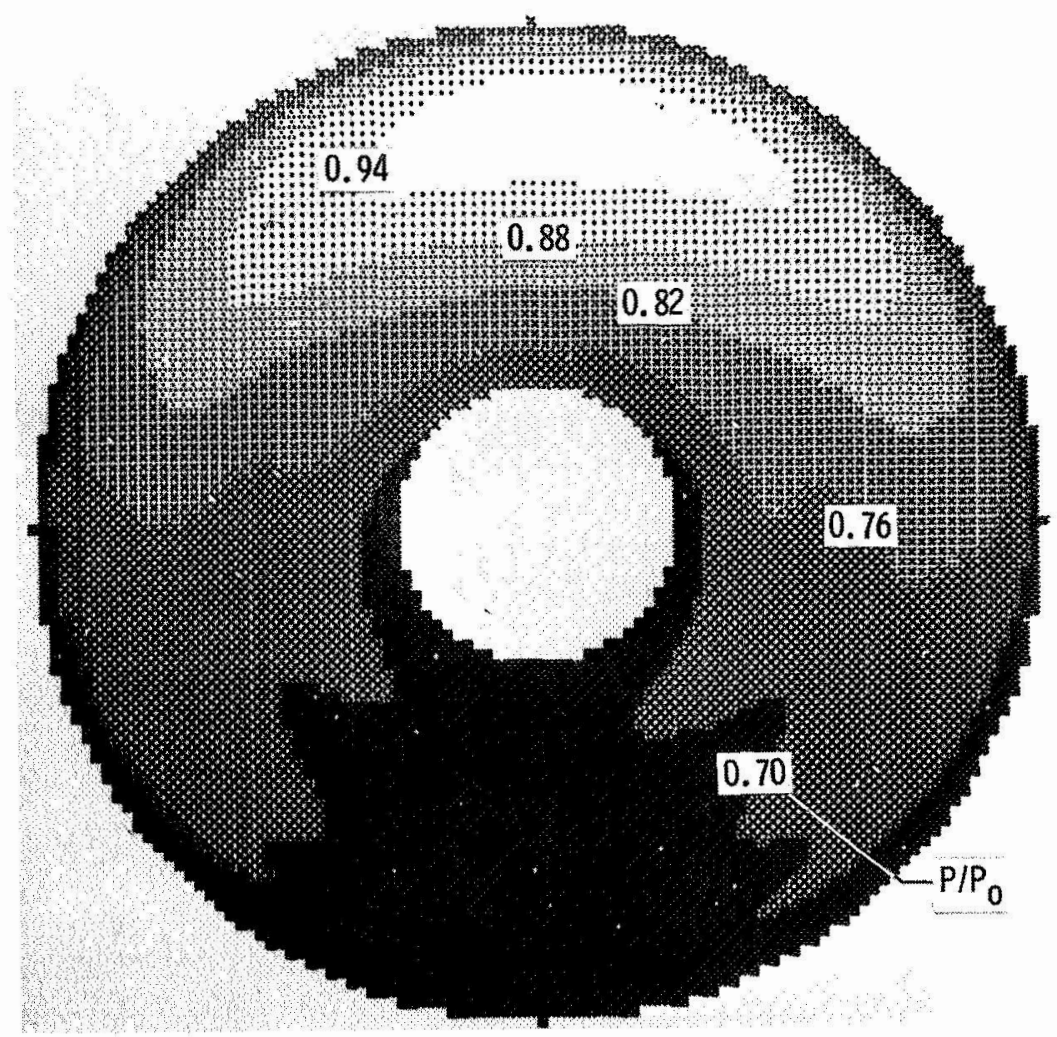

Steady-state; $\bar{P} / P_{0}=0.769$

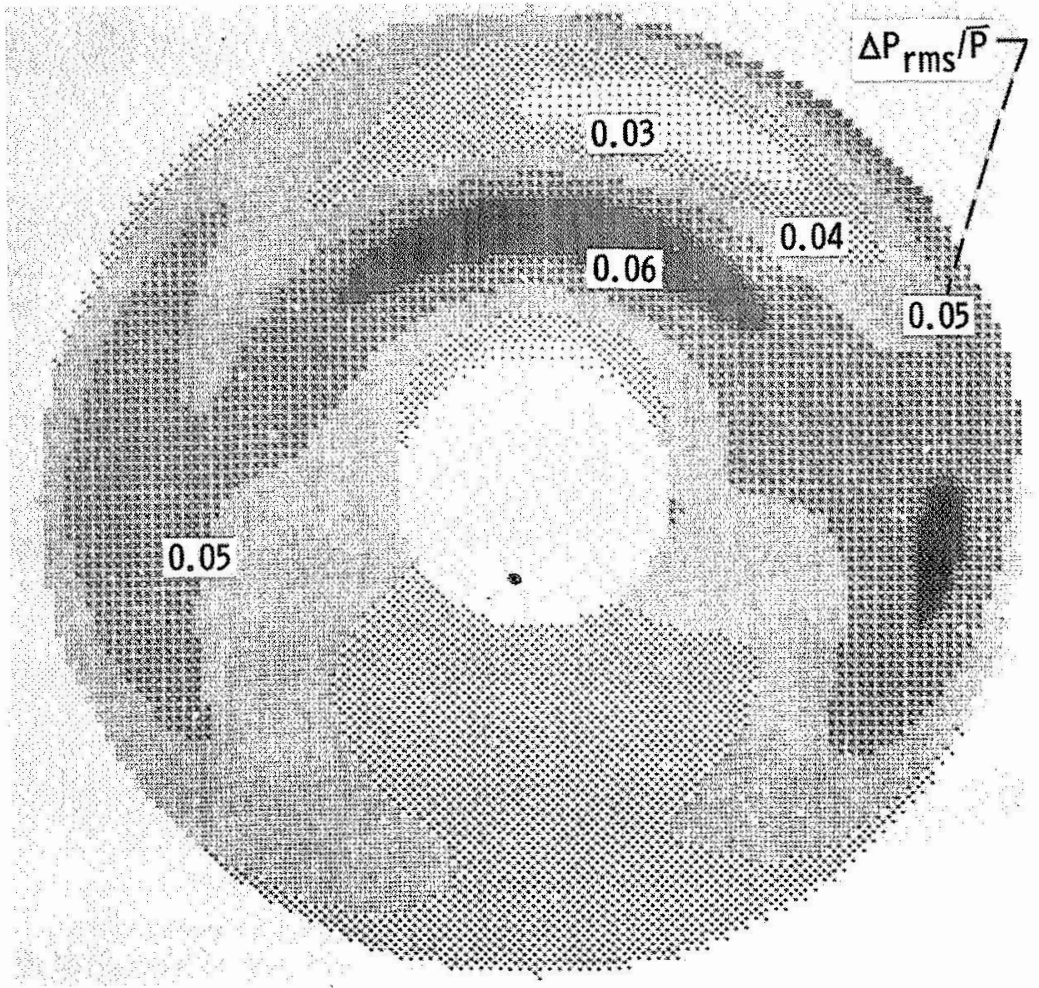

Dynamic; $\left(\overline{\Delta P}_{r m s}\right) / \bar{P}=0.046$.

(b) $a=5^{\circ}$ stall point.

Figure 7. - Concluded. 


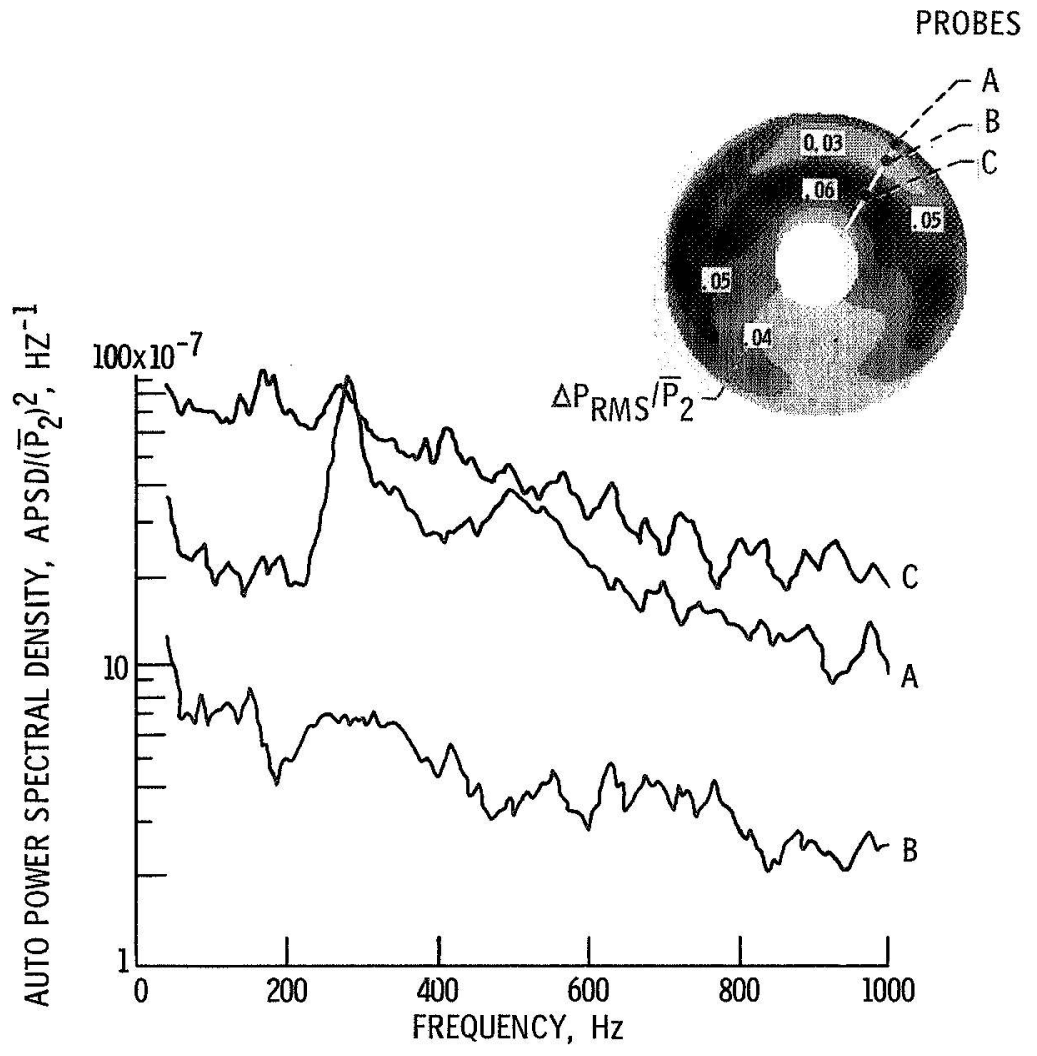

Figure 8. - Frequency content of total pressure fluctuations. $\alpha=5^{0}$ stall point. 


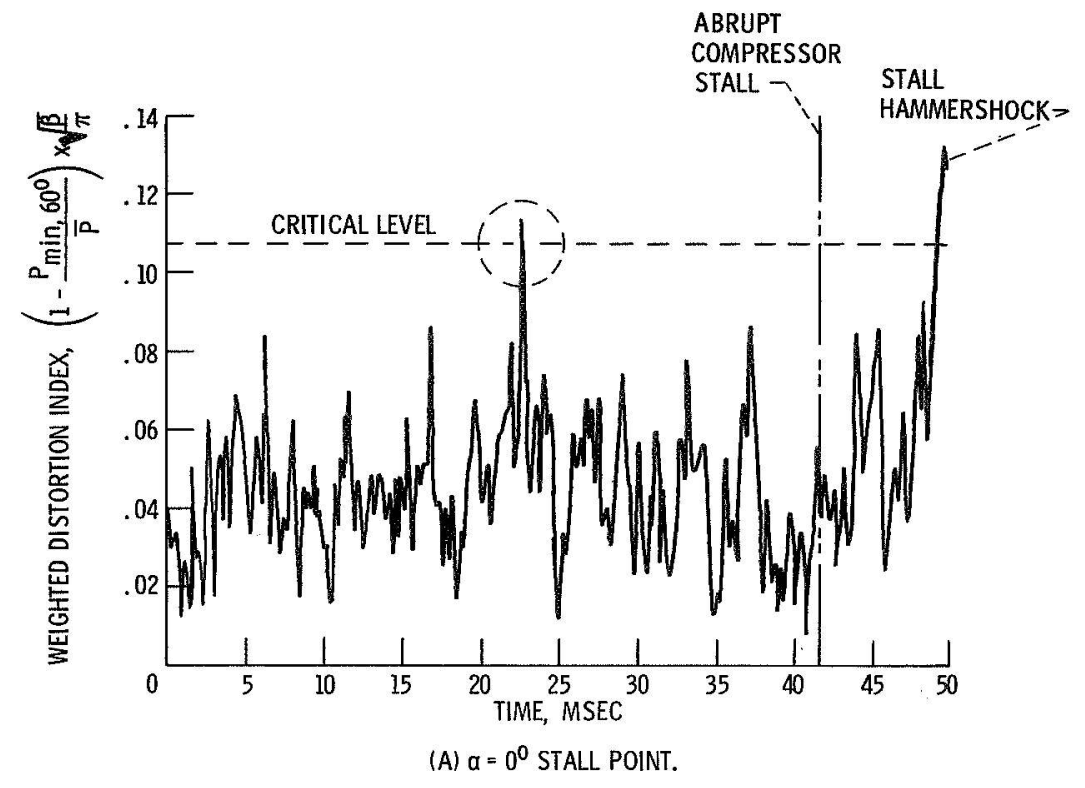

Figure 9. - Instantaneous distortion history.

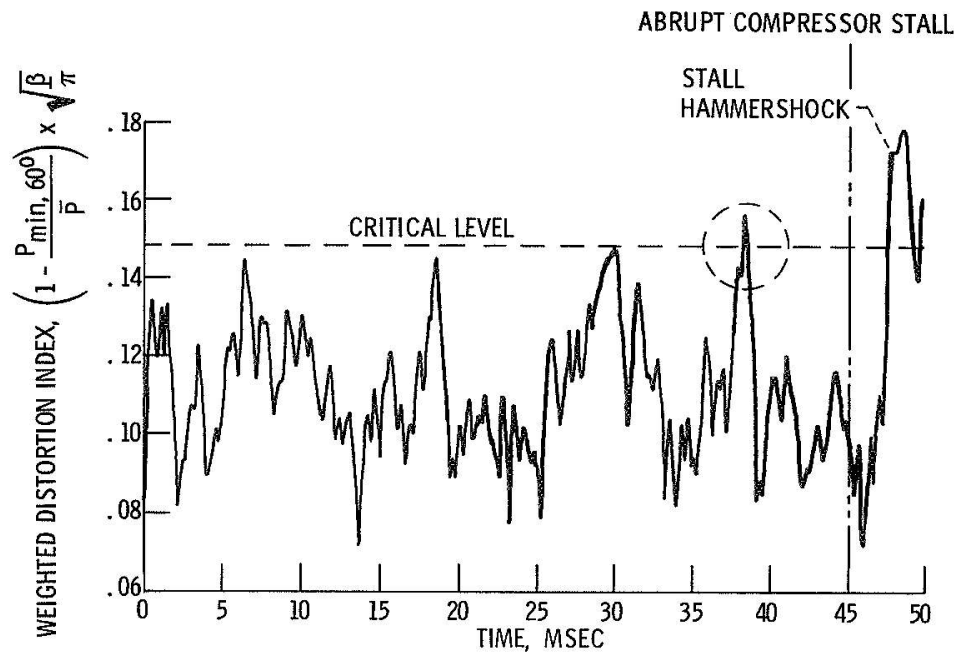

(B) $\alpha=5^{\circ}$ STALL POINT.

Figure 9. - Concluded. 


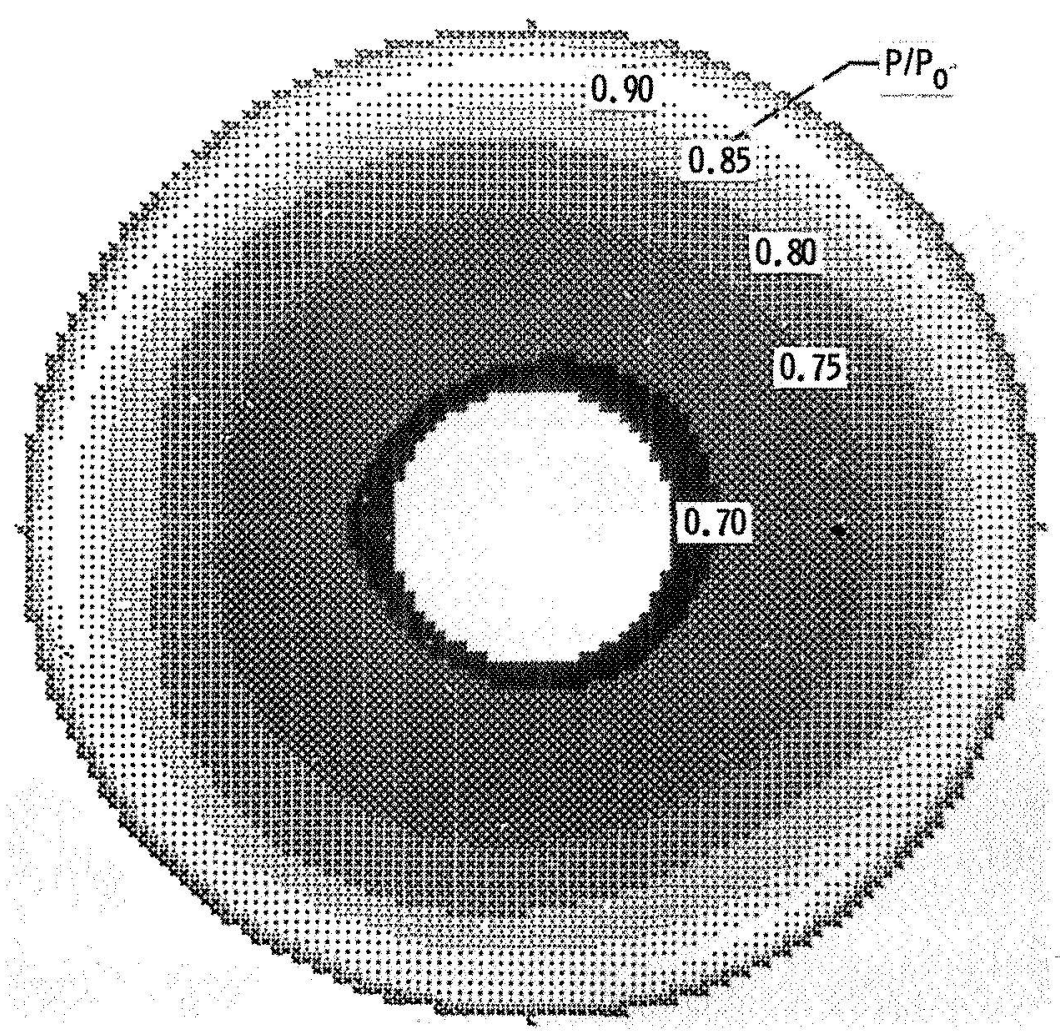

Steady-state; $\bar{P} / P_{0}=0.788$.

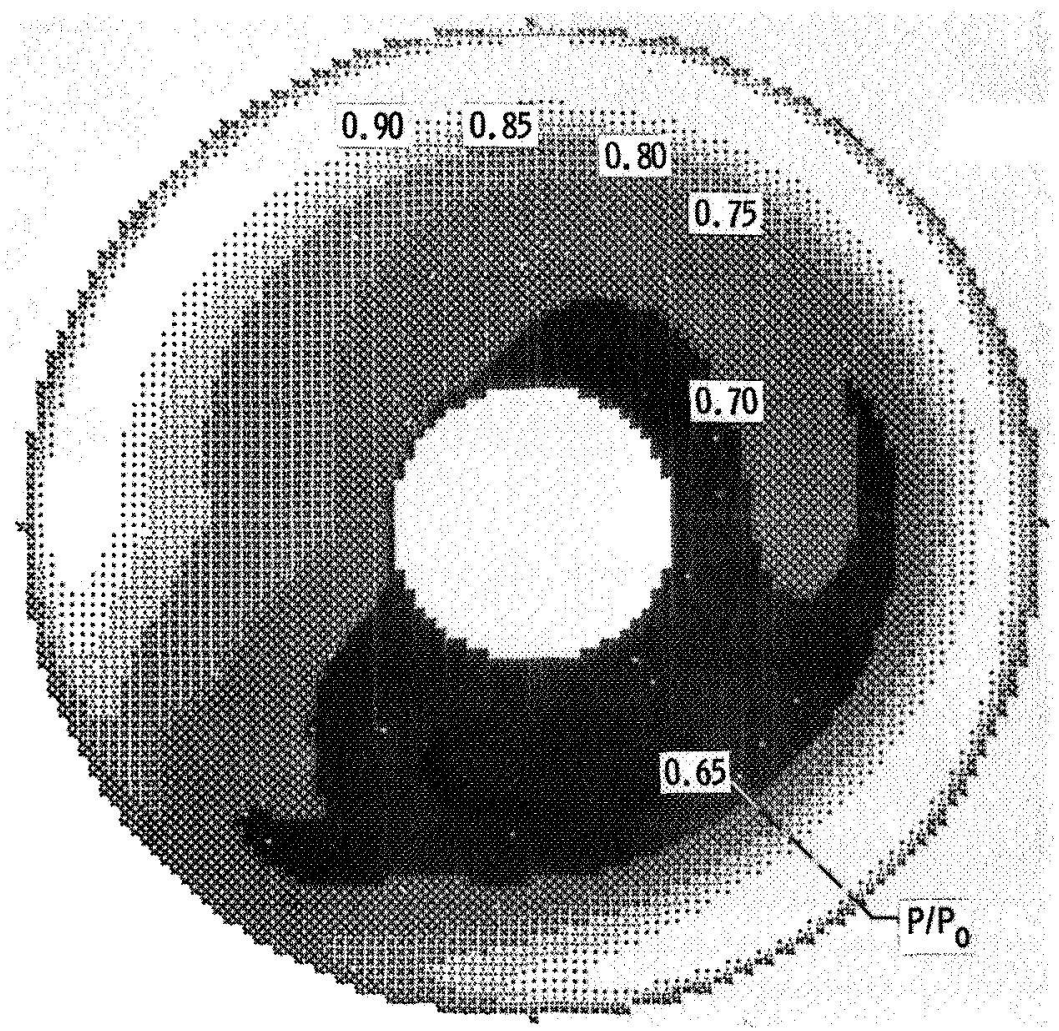

Peak instantaneous; time $=\mathbf{2 2 . 6 2 5}$ milliseconds.

(a) $a \approx 0^{\circ}$ stall point,

Figure 10, - Steady-state and peak instantaneous distortion contours. 


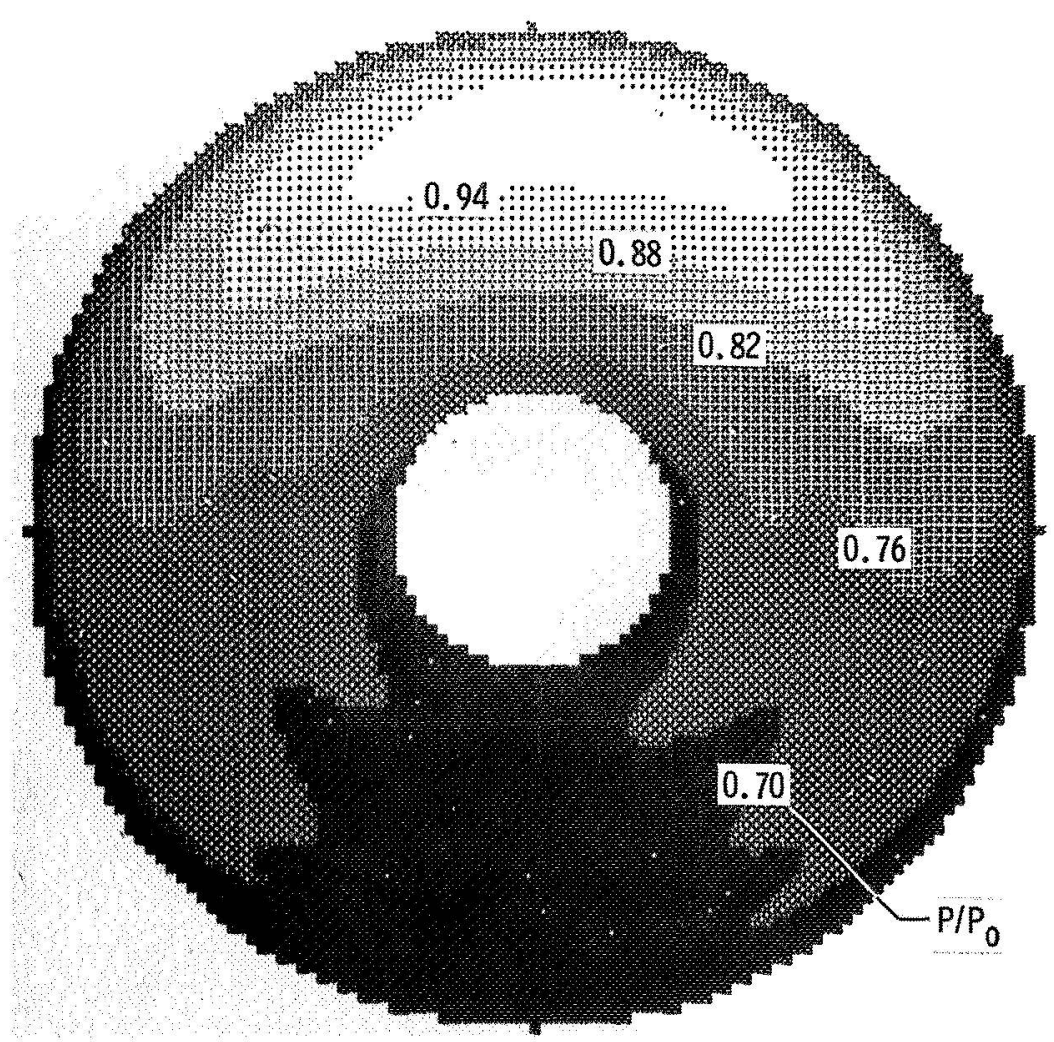

Steady-state; $\bar{P} / P_{0}=0.769$.

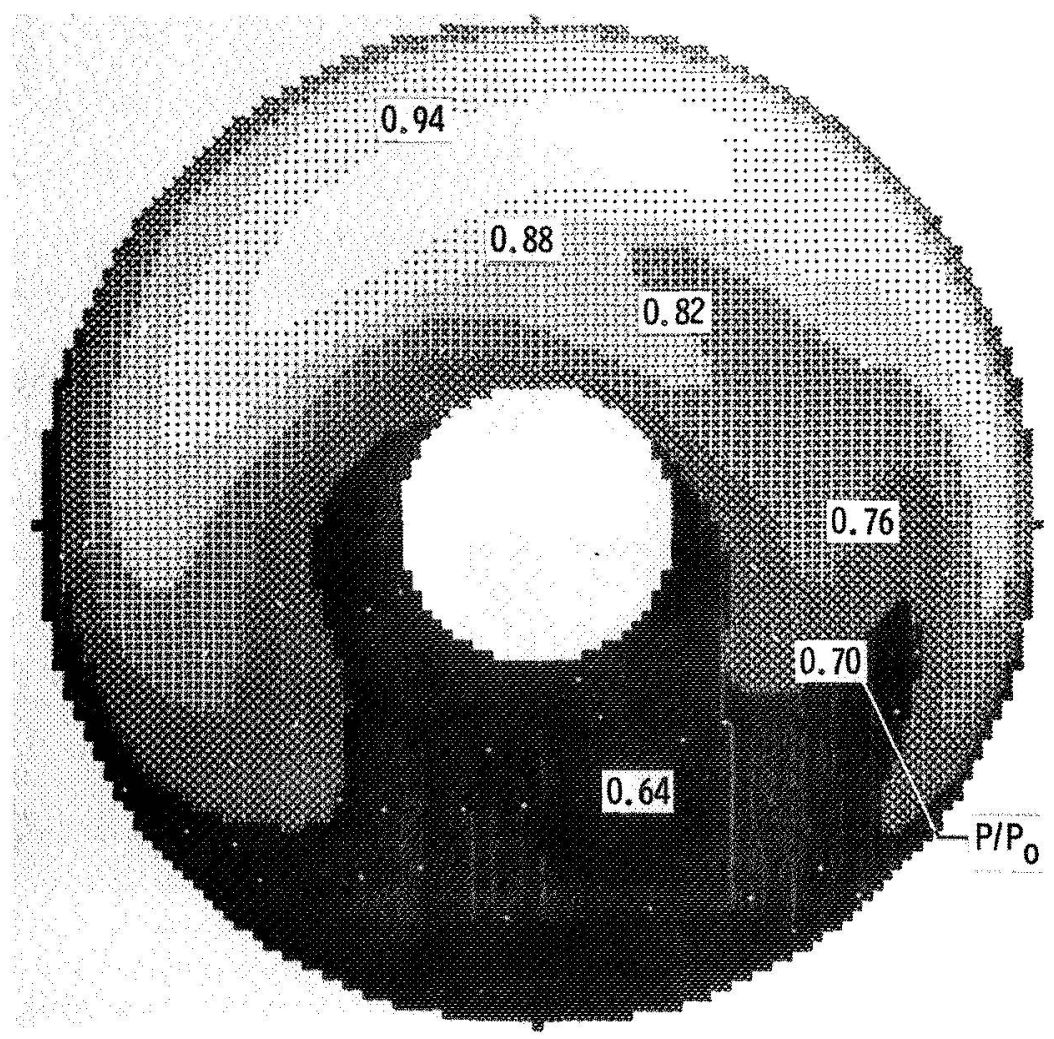

Peak instantaneous; time $=38.50$ milliseconds.

(b) $5^{\circ}$ stail point.

Figure 10. - Concluded. 


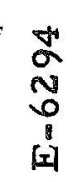

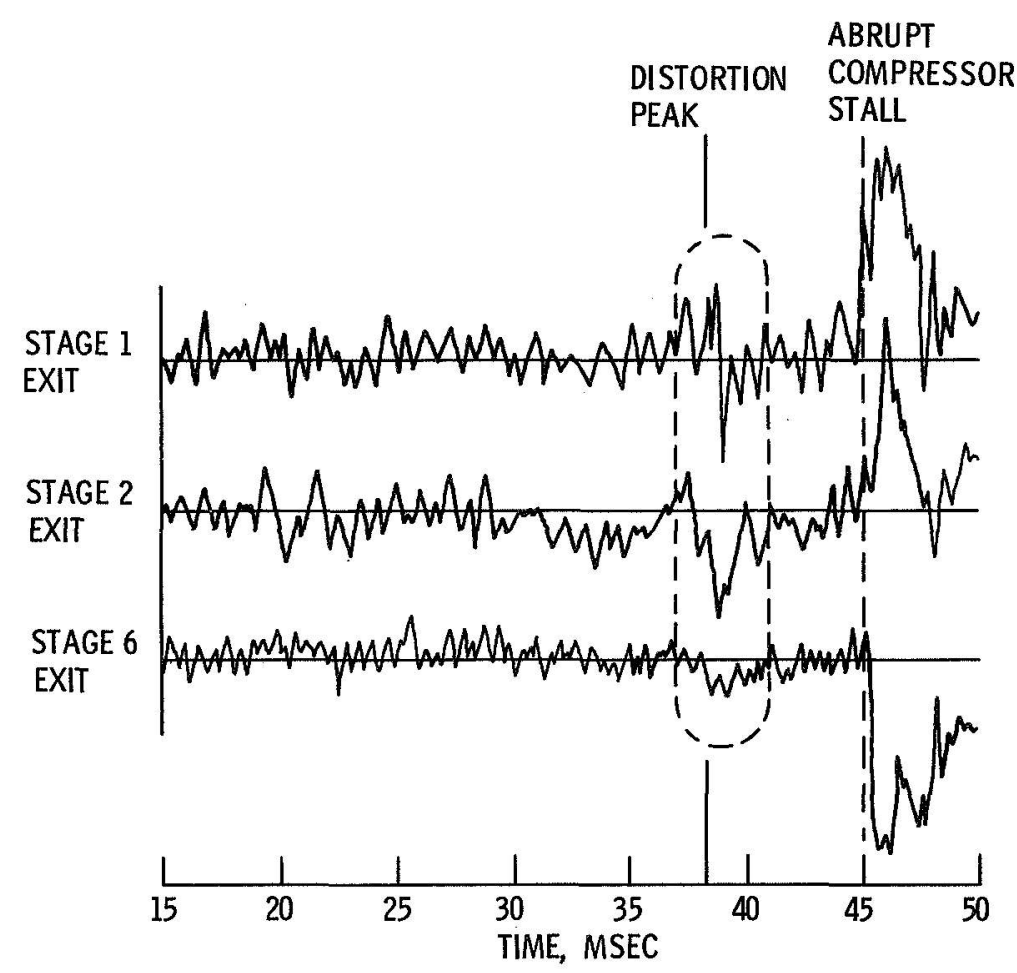

Figure 11. - Interstage static pressure histories. $a=5^{0}$ stall point. 